REGARDS

SUR L'ECONOMIE ALLEMANDE

BULLETIN ECONOMIQUE DU CIRAC
Regards sur l'économie allemande

Bulletin économique du CIRAC

$68 \mid 2004$

Varia

\title{
Opinion : les Allemands soutiennent les réformes
}

Isabelle Bourgeois

\section{OpenEdition}

Journals

Édition électronique

URL : http://journals.openedition.org/rea/3633

DOI : $10.4000 /$ rea.3633

ISBN : 978-2-8218-0832-4

ISSN : 1965-0787

Éditeur

CIRAC

Édition imprimée

Date de publication : 1 octobre 2004

Pagination : 33-34

ISSN : 1156-8992

Référence électronique

Isabelle Bourgeois, "Opinion : les Allemands soutiennent les réformes », Regards sur l'économie allemande [En ligne], 68 | octobre 2004, mis en ligne le 29 avril 2009, consulté le 15 septembre 2020. URL : http://journals.openedition.org/rea/3633

Ce document a été généré automatiquement le 15 septembre 2020.

(C) CIRAC 


\title{
Opinion : les Allemands soutiennent les réformes
}

\author{
Isabelle Bourgeois
}

\section{Mécontentement à propos de la... lenteur des réformes}

1 Les réformes du gouvernement fédéral bénéficient d'un large appui dans l'opinion. Même si, sur certains points, l'opinion grogne épisodiquement, c'est dû bien plus au rythme accéléré des profonds changements de ces deux dernières années, et aussi, paradoxalement, à une sorte d'impatience; les réformes ne produisent pas assez vite leurs effets pour dynamiser la compétitivité du pays. Car les Allemands semblent conscients de la faiblesse de leur économie : ils ne sont plus qu'un tiers (33\%) à estimer que "l'économie allemande va plutôt mieux " que celle de ses voisins européens; en 1994, ils étaient encore le double (66\%). C'est ce qui ressort d'un sondage sur la situation économique de l'Allemagne publié en août 2004 par la Fédération bancaire allemande; commandité à l'institut ipos de Mannheim, il avait été réalisé en avril auprès d'un échantillon représentatif de 1546 personnes de plus de 18 ans. Interrogés sur l'état du système de protection sociale, ils sont convaincus de la nécessité de le réformer d'urgence : $50 \%$ estiment "qu'il y a de gros problèmes ", et $42 \%$, que «le système est au bord de l'implosion ». Ils sont tout aussi nombreux à considérer que les réformes engagées par le gouvernement Schröder "ne suffisent pas» $(92 \%)$ et «qu'elles ne vont pas assez vite» (84\%).

\begin{tabular}{l}
$\begin{array}{l}\text { Pour assurer l'avenir de l'économie sociale de marché : avons-nous besoin de plus de marché, donc } \\
\text { de plus de libre concurrence, de plus de protection sociale, ou n'y a-t-il rien à changer? }\end{array}$ \\
\hline
\end{tabular}




\begin{tabular}{|c|c|c|c|c|c|}
\hline Plus de protection sociale & $48 \%$ & $48 \%$ & $43 \%$ & $37 \%$ & $41 \%$ \\
\hline Pas de changement & $22 \%$ & $14 \%$ & $18 \%$ & $14 \%$ & $8 \%$ \\
\hline \multicolumn{6}{|c|}{$\begin{array}{l}\text { La garantie de notre prospérité est-elle d'abord l'affaire de chacun d'entre nous ou est-elle d'abord } \\
\text { l'affaire de l'Etat?. }\end{array}$} \\
\hline L'affaire de chacun & $47 \%$ & $44 \%$ & $55 \%$ & $58 \%$ & $61 \%$ \\
\hline L'affaire de l'Etat & $47 \%$ & $49 \%$ & $39 \%$ & $36 \%$ & $34 \%$ \\
\hline \multicolumn{6}{|c|}{$\begin{array}{l}\text { Les gens devraient moins se reposer sur l'Etat; ils devraient plus largement prendre en mains eux } \\
\text { mêmes leurs problèmes }\end{array}$} \\
\hline D'accord & - & - & - & - & $84 \%$ \\
\hline Pas d'accord & - & - & - & - & $14 \%$ \\
\hline \multicolumn{6}{|c|}{$\begin{array}{l}\text { Pour garantir les retraites, faut-il augmenter les cotisations, ou chacun devrait-il faire un effor } \\
\text { pour compléter individuellement sa retraite? }\end{array}$} \\
\hline Augmenter les cotisations & - & - & - & $21 \%$ & $18 \%$ \\
\hline $\begin{array}{l}\text { Accroître la participation } \\
\text { individuelle }\end{array}$ & - & - & - & $72 \%$ & $77 \%$ \\
\hline \multicolumn{6}{|c|}{$\begin{array}{l}\text { A l'avenir, les conventions collectives devraient-elles continuer à être conclues, comme } \\
\text { aujourd'hui, par les syndicats et les fédérations patronales, uniformément pour l'ensemble d'une } \\
\text { branche, ou devraient-elles être négociées, entreprise par entreprise, par la direction et le consei } \\
\text { d'établissement? }\end{array}$} \\
\hline A l'échelon de la branche & $55 \%$ & $45 \%$ & $45 \%$ & $42 \%$ & $30 \%$ \\
\hline Au niveau de l'entreprise & $36 \%$ & $49 \%$ & $46 \%$ & $51 \%$ & $63 \%$ \\
\hline \multicolumn{6}{|c|}{$\begin{array}{l}\text { Au sein de la même branche, le temps de travail devrait-il être réglementé uniformément, ou les } \\
\text { entreprises devraient-elles pouvoir le négocier individuellement en fonction de l'utilisation des } \\
\text { capacités et de la conjoncture? }\end{array}$} \\
\hline $\begin{array}{l}\text { Uniformément au niveau } \\
\text { de la branche }\end{array}$ & - & - & - & - & $16 \%$ \\
\hline $\begin{array}{l}\text { Au niveau de chaque } \\
\text { entreprise }\end{array}$ & - & - & - & - & $81 \%$ \\
\hline \multicolumn{6}{|c|}{$\begin{array}{l}\text { A votre avis : les entreprises embaucheraient-elles plus de salariés si elles pouvaient les licencier } \\
\text { hélas, plus facilement? }\end{array}$} \\
\hline oui & - & - & - & - & $60 \%$ \\
\hline
\end{tabular}


non

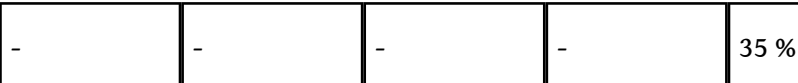

Source : Bundesverband deutscher Banken/Ipos, Interesse n 8/2004. NB: les réponses «n.s.p. » ne figurent pas dans ce tableau. Sondage réalisé en avril 2004 auprès d'un échantillon représentatif de 1546 électeurs.

\section{Pour des réformes, mais sans confiance dans le politique}

2 Ils sont conscients de la nécessité des réformes. $86 \%$ répondent «non » à la question : "pensez-vous que nous pourrons continuer à l'avenir à financer nos hauts salaires, notre faible durée du travail et nos longs congés?». Une large majorité $(57 \%)$ est « entièrement/ assez d'accord» avec la phrase suivante: «à l'avenir, il nous faudra tous travailler plus sans gagner plus pour autant » $(42 \%$ toutefois ne partagent « pas du tout/plutôt pas » cette opinion. Parmi les actifs occupés interrogés, $54 \%$ accepteraient de voir leur salaire réduit de $5 \%$ ( $44 \%$ non) ; voici dix ans, ils n'étaient encore que $43 \%$. Les Allemands sont bel et bien conscients aujourd'hui de la nécessité des réformes structurelles. Et pourtant, ils n'aiment guère le mot "réformes", auquel ils trouvent majoritairement (à $80 \%$ ) une connotation négative. Elle peut s'expliquer par la faible confiance qu'ils ont dans la «capacité du politique à résoudre les problèmes économiques du pays » : $75 \%$ des sondés l'estiment non capable (en 2002, ils n'étaient que $66 \%)$. Ce scepticisme traverse toutes les obédiences, les moins sceptiques se recrutant parmi les électeurs SPD ( $56 \%$ de réponses "non capable»), les plus sceptiques étant proches du parti communiste PDS (84\%) ou du parti libéral FDP (87\%). Le gouvernement fédéral, l'actuel comme celui qui lui succèdera en 2006, devra revoir sa communication - non pas pour expliquer le pourquoi des réformes, mais pour convaincre de sa compétence...

\section{Moderniser l'économie sociale de marché pour la préserver}

Qui dit réformes dit aussi choix de société. Or les Allemands ne veulent pas de modèle libéral. Ils restent foncièrement attachés à l'économie sociale de marché qui fonde le « modèle rhénan » en conciliant l'économique et le social, le travail et le capital. Ils sont encore $56 \%$ à estimer que ce modèle «a fait ses preuves ». Leur confiance a baissé en dix ans : ils étaient alors $73 \%$ à le penser. A l'ouest, elle est plus prononcée qu'à l'est ( $58 \%$ contre $47 \%$ ), ce qui s'explique aisément par les cheminements économiques et sociaux respectifs. Mais peut-être y a-t-il aussi un problème de compréhension; "économie sociale de marché " est un mot savant et abstrait. Car lorsqu'ils sont interrogés sur les valeurs qui sous-tendent ce modèle, ils se montrent nettement plus affirmatifs. Ainsi, ils plébiscitent la notion de responsabilité individuelle. $61 \%$ des sondés répondent « oui » à la question suivante : « la garantie de notre prospérité estelle d'abord l'affaire de chacun d'entre nous ou est-elle d'abord l'affaire de l'Etat? ». Ils n'étaient encore que $47 \%$ en 1994. Cette progression est l'œuvre de la pédagogie des réformes. Mais rapprochée de la faible confiance que les Allemands disent avoir dans la capacité du politique à mener les réformes à bien, elle exprime aussi une 
réappropriation du principe de subsidiarité. Autrement dit: de la conscience que la prospérité collective est aussi le fruit des efforts individuels. Voilà pourquoi, malgré leur scepticisme de détail, les Allemands adhèrent foncièrement aux réformes. (IB)

INDEX

Mots-clés : opinion publique, sondage, réforme, politique économique, société 